\title{
Do Local Elites Capture Natural Disaster Reconstruction Funds?
}

\author{
Yoshito Takasaki \\ University of Tsukuba
}

\author{
Contact Information: \\ Yoshito Takasaki \\ Graduate School of Humanities and Social Sciences \\ University of Tsukuba \\ 1-1-1 Tennodai, Tsukuba \\ Ibaraki 305-8571 Japan \\ Tel./fax: +81298536280 \\ E-mail address: takasaki@sk.tsukuba.ac.jp
}

April 26, 2010

Forthcoming in Journal of Development Studies

\section{Acknowledgments}

I wish to thank my field team - Jonati Torocake, Viliame Manavure, Viliame Lomaloma, and 16 enumerators - for their advice, enthusiasm, and exceptional efforts on behalf of this project. Special thanks are owed to the Fijians of the region who so willingly participated in the survey. This research has been made possible through support provided by the Sumitomo Foundation, the Japan Society for the Promotion of Science, and the Ministry of Education, Culture, Sports, Science and Technology in Japan. Any errors of interpretation are solely the author's responsibility. 


\title{
Do Local Elites Capture Natural Disaster Reconstruction Funds?
}

\begin{abstract}
Using original survey data with rich, direct measures of local elites in rural Fiji, this paper examines potential elite capture in the allocation of natural disaster reconstruction funds. Allocations of housing construction materials - both receipt and amount received - across villages, clans, and households are strongly targeted on cyclone damage, and local elites do not receive larger benefits over time. As the supply of reconstruction funds is limited during early periods, more severely affected victims do not receive benefits early, while clan leaders and elite clans do receive benefits early within villages.
\end{abstract}

\section{Introduction}

Vulnerability to natural disaster is a major barrier to development, and augmenting the capacity for effective disaster management is critically important. Frequent reports point to an inefficient distribution of disaster relief by uncoordinated relief agents who lack pertinent information about the damage. This is not surprising, because relief agents give a higher priority to the speed of response than to evidencebased decision making (de Ville de Goyet, 2008). Only recently has empirical research started to shed light on the performance of relief targeting. Morris and Wodon (2003) find that among Honduran victims of Hurricane Mitch, allocations of emergency aid were targeted on recipients' damage, but the amounts received were not.

As time passes, the main actions of disaster management shift from relief to recovery and reconstruction (de Ville de Goyet, 2008), and many believe that the allocation of relief, recovery, and reconstruction funds becomes more efficient as damage 
information accumulates and agents' coordination becomes more effective. Probably because of this perception, as well as a lack of data, empirical research on targeting reconstruction funds during post-emergency periods is lacking. This paper examines the allocation of housing reconstruction funds among cyclone victims in rural Fiji. Understanding the performance of targeting reconstruction funds as a primary allocation mechanism is important, but is not a main focus of the paper. Rather, my main goal is to address a question that researchers have not yet explored, but has potential to be of critical importance: Do local elites capture natural disaster reconstruction funds?

Elite capture occurs when a powerful minority alters the nature of a particular program in their favor. Researchers have given considerable attention to elite capture as a potential drawback of participatory or decentralized development (World Bank, 2002; Mansuri and Rao, 2004). Bardhan and Mookherjee (2000) theoretically examine the factors that might affect whether elite capture is more likely to occur at the local or national level, showing that higher income inequality results in more local capture. Consistent empirical findings have been obtained in community-based programs in Asia and Latin America, such as India's employment generation program (Bardhan and Mookherjee, 2006), Bangladesh's Food-for-Education Program (Galasso and Ravallion, 2005), and Ecuador's Social Fund investment projects (Araujo et al., 2008).

Platteau and Abraham (2002) argue that capture problems are also significant in more egalitarian lineage-based societies in Sub-Saharan Africa because of community imperfections with social stratification: Cultural norms restrict non-elites' access to information and emphasize consensual decision-making. In Fiji and many other Pacific Island states, kin-based hierarchies play a central role in local governance (Turner, 1992), 
underlying potential elite capture. In a related study, Leeson and Sobel (2008) find that a greater amount of disaster relief received is associated with higher public corruption across the United States.

Most empirical works consider benefit allocation to be biased toward elites as evidence of elite capture. Such allocation patterns, however, can occur because of cultural norms that prioritize elites without their misappropriations. This is because allocations neutral to the community hierarchy disrupt the social equilibrium, resulting in conflict that community members - both elites and non-elites - seek to minimize. Some studies show that elites' capturing program benefits is not necessarily pernicious to community development, because elites might take actions that benefit non-elites (i.e., 'benevolent capture') (Mansuri and Rao, 2004). Examples include broad-based satisfaction with outcomes of the elite-driven social fund process in Jamaica (Rao and Ibáňez, 2003), higher maintenance of infrastructure projects in communities with hereditary leaders in Pakistan (Khwaja, 2001), and pro-poor benefit allocation in communities controlled by elites in Indonesia's poverty alleviation project (Dasgupta and Beard, 2007).

This paper highlights elite domination as a potential secondary allocation mechanism of reconstruction funds. It is very difficult for researchers to distinguish between capture- and norm-based dominations, which are not mutually exclusive, because observers have difficulty observing elites' misappropriations and non-elites hesitate to reveal them to avoid social sanction. The studies cited above do not show why elite domination leads to benevolent outcomes. Regardless of the underlying process of elite domination, it raises the question of the extent to which the allocation is equitable. 
Understanding the efficiency and equity of disaster management is of great importance in small island states with their increasing dependency on emergency aid from donors and deteriorating indigenous coping mechanisms (e.g., Bertram, 1986; Campbell, 1984). In contrast to extensive anthropological studies, there are very few economic studies of the Pacific region based on household survey data.

Though my Fijian data, like others, have no direct information to distinguish between capture and norms, its three unique features enable me to better explore elite domination patterns. First, since households in each village are stratified by their kin group (clan) and elite status, direct measures of elite status are available. In standard household surveys, in contrast, elite status is often unobservable to researchers, and even if it is observable, there are too few elites to make a statistical analysis possible. Most empirical studies on community-based development programs rely on measures of consumption, income, or asset inequality to examine elite capture with the assumption that power is correlated with wealth; instead, this paper directly identifies elite dominance.

Second, a direct comparison of relief and reconstruction is made possible by original survey data gathered in 2005 in the same area as my other study (Takasaki, forthcoming), but from many more villages and households than my original sample in 2003. Distinct from my companion work on relief allocation within villages in the six months after the cyclone, this paper examines the allocation of housing reconstruction funds at the village, clan, and household levels over a three-year period.

Third, information about the timing of receipt of reconstruction funds enables me to explore the temporal dimension of targeting and elite domination. Let me define 
temporal targeting as follows: The larger the damage, the earlier the receipt or the greater the amount received in early periods. Temporal elite domination is defined analogously: Local elites receive benefits earlier or receive greater benefits during early periods than non-elites. These patterns can be a result of either capture or norms, though they are treated as early capture in previous works (Lanjouw and Ravallion, 1999). In contrast, non-temporal targeting and non-temporal elite domination, respectively, do not involve a temporal dimension: The greater the damage, the higher the probability of receipt or the greater the amount received, and local elites are more likely to be a recipient or to receive a greater amount than non-elites.

Main findings of the paper are summarized as follows. Non-temporal targeting in allocations of housing reconstruction funds - both receipt and amount received - is strong at the village, clan, and household levels over time, and neither non-temporal nor temporal elite domination of amounts received exists at any level. A limited supply of funds during early periods of extended reconstruction, however, precludes temporal targeting in receipt and amounts received at any level, and temporal elite domination of receipt by clan leaders and elite clans occurs within villages.

The rest of the paper is organized as follows. Section II describes elite status in Fijian society and the data. Section III provides a description of cyclone damage and reconstruction. Section IV offers descriptive evidence of targeting and elite domination. Section V discusses the econometric specification, which is followed by estimation results in Section VI and discussions in Section VII. The last section concludes.

\section{Elite status and data}


Each native Fijian belongs to a lineage of the vanua-yavusa-mataqali-tokatoka hierarchy illustrated in Figure 1 (Ravuvu, 1983). Each class of kin group (except for vanua, a highest-order class) is a subset of its higher-order class (e.g., yavusa 2 consists of mataqali 1 and 2). Vanua ranges over several villages, roughly matching a district; there is one or a few yavusa in each village.

Kin-based elite status is defined as follows. First, Fijian villages are categorized into either one with a highly ranked vanua chief who assumes traditional duties across villages (chief's village), or other (village 1 vs. 2). Second, mataqali (henceforth called clan) is either one with a yavusa or mataqali chief who assumes traditional duties within the village (chief's clan), or other (mataqali 1 vs. 2). Third, some Fijian households have a kin leader (including kin chief) defined at the yavusa, mataqali, or tokatoka level (there is no takatoka chief) who plays a major role in the group's decision-making and negotiations among groups in the village (clan leader), and others do not (household 1 vs. 2). Village chiefs are shared by some clan leaders and are not necessarily kin chiefs.

These kin groups and elite status are traditionally assigned and permanent, underlying Fijian livelihoods as well as local governance and ritual (Turner, 1992). In particular, land is communally owned by mataqali (about $83 \%$ of the country's total land is communal), and customary rights for coastal fishing are held by vanua or several yavusa. Local elite status is also held by leaders of groups other than kin groups in the village, such as church, women's, and school groups (non-clan leaders). Non-clan leaders include gatekeepers (turaga ni koro), who handle most matters in connection with the local government (receiving information and materials and distributing them to 
villagers); the number of gatekeepers in the present data is too small for statistical analysis. Non-clan leadership is neither permanent nor directly related to kinship.

On 13 January 2003, Cyclone Ami swept over the northern and eastern regions of the Fiji Islands (Ami was the only cyclone in the northern region from 1991 through 2005, McKenzie et al., 2005). In July-September 2005, I conducted a household survey in Cakaudrove Province in the northern region. The province is located mainly on Vanua Levu Island and Taveuni Island, the second- and third-largest islands in the country, which significantly lag behind the largest island, Viti Levu, where the state capital, two international airports, and most tourism businesses are situated. The province has 134 villages in 16 districts, among which one has two chief's villages, another has none, and the other 14 have one. In each district, villages are stratified by chief's village status; 15 chief's villages were sampled (one chief's village was not because of a political concern), and another 28 villages with distinct environmental and economic conditions were intentionally chosen.

The sampling frame is a household census made by enumerators in each village; the cyclone caused no casualties and only three households left the village after it occurred. In each village, households are stratified by tokatoka and a combination of clan/non-clan leadership status and major asset holdings, such as shops (i.e., whether any leadership status or major asset is held); the population consists of 1,916 households in 242 tokatoka, constituting 443 strata. In each stratum, households were randomly sampled with selection probability negatively related to the size of the stratum, yielding 967 sample households (50\% of the population). Only a small proportion of households were not interviewed, mostly because of their temporary absence during the survey; thus, 
attrition bias is unlikely to be a major concern. Overall, the survey covered 906 households, 234 tokatoka, and 146 mataqali in 43 villages.

Descriptive statistics at the village, clan, and household levels, respectively, are reported in panels $\mathrm{A}, \mathrm{B}$, and $\mathrm{C}$ of Table 1: $35 \%$ of villages, $17 \%$ of clans (mataqali), and $19 \%$ of households are chief's villages, chief's clans, and clan leaders, respectively; there are non-clan leaders in all villages, $55 \%$ of clans, and $10 \%$ of households. The data thus contain sufficient variations of local elites for statistical analysis.

\section{III.Cyclone damage and reconstruction}

The total damage across the country caused by Cyclone Ami is estimated at $\mathrm{F} \$ 104$ million ( $\mathrm{F} \$ 1=\mathrm{US} \$ .60)$, of which dwelling damage is $\mathrm{F} \$ 22$ million and crop damage is F $\$ 40$ million (National Disaster Management Office, 2003). According to respondents' subjective assessments, $62 \%$ of residents' dwellings - a main house and/or free-standing units, such as the kitchen, shower, and toilet (not all households have such units, as such facilities are often located inside the main house) - were damaged in the sample (panel C of Table 1): $19 \%$ and 34\% of main houses were completely destroyed and partially damaged, respectively, and 53\% of households experienced damage to freestanding units ( $44 \%$ of households experienced both damages). The mean value of total dwelling damage was $F \$ 1,074$, or equivalently about $10 \%$ of mean household earned income per annum at the time of interviews. Dwelling damage was experienced by at least one household in all villages and $88 \%$ of clans (panels A and B, respectively).

The Red Cross, other nongovernmental organizations, and governments provisioned emergency relief. While almost all households received emergency food aid (30\% of their food consumption over six months after the cyclone, on average), a small 
proportion of victims received tarpaulins that could be used as emergency shelters and for temporary dwelling repair (Takasaki, forthcoming).

Housing reconstruction programs followed. Construction materials were provisioned, and if needed, carpenters were sent to villages to help build new houses (villagers helped each other with rebuilding and repairing). In the survey, each household was asked whether it received construction materials, and the recipient was asked about the year and month of receipt and the monetary value of construction materials received. One quarter of households were recipients, and the mean amount in the whole sample was $\mathrm{F} \$ 685$; the mean amount among recipients was $\mathrm{F} \$ 2,821$, which is almost the same as the mean value of total dwelling damage in the same sub-sample. At least one recipient household was in $54 \%$ of clans and $88 \%$ of villages.

After the cyclone, a new house was built by $9 \%$ of households, almost all of which experienced dwelling damage, especially complete destruction of their main house (results not shown). Among those with a completely destroyed main house, more than half of recipients built a new house, while $20 \%$ of non-recipients did so (information about repairing is lacking). Thus, provisions of construction materials greatly helped reconstruction, but those for new house building were insufficient and self-reconstruction was relatively common.

Indeed, provisions of construction materials took time. Figure 2 depicts the numbers of households that received construction materials and the mean amounts among recipients by quarter (the last quarter, 2005-3, when interviews were conducted and thus for which the record is incomplete, is included in the regression analysis below; the results are similar when it is excluded). The numbers of recipients and the amounts 
received were small during early quarters and increased later: 2004-1 onward and 2004-4 onward, respectively. That is, housing reconstruction programs augmented in scale one year after the cyclone, and provisions of full construction materials for new house building were further delayed (in 2003-3 only one recipient received them).

\section{Descriptive analysis of targeting and elite domination}

Non-temporal targeting of construction materials in the three-year period, 20032005, was strong at the village, clan, and household levels: Both receipt and amounts received are strongly positively correlated with almost all damage measures (results not shown) and the error of inclusion (leakage) is very small - only $2 \%$ of recipients were households that experienced no dwelling damage (panel $\mathrm{C}$ of Table 1). The limited supply of reconstruction funds, however, resulted in a significant error of exclusion (under-coverage) - 60\% of victims with a damaged dwelling were not recipients (results not shown). While households with a completely destroyed main house were targeted ( $48 \%$ of recipients), under-coverage was still common $(35 \%$ of such victims were not recipients). As the supply of full construction materials for new house building was limited, small provisions were targeted toward victims with a partially damaged main house and with damaged free-standing units ( $42 \%$ and $8 \%$ of recipients, respectively).

The limited supply of construction materials during early periods of reconstruction precluded temporal targeting: Correlation analysis in each year indicates that households with severer damage were late, not early, recipients, while benefit amounts were always targeted on damage (results not shown); similar patterns are also found at the clan and village levels. 
Descriptive evidence of elite domination is limited to the following. First, chief's clans and clans with non-clan leaders are more likely to be recipients in the three-year period, but not in early periods (panel B of Table 1). Second, the amounts received in early periods, but not in the three-year period, among recipient households are positively correlated with clan leaders (results not shown). To see whether these patterns hold when controlling for cyclone damage, a primary determinant of allocation, is a task of the remaining sections.

\section{Econometric specification}

I conjecture that allocation of construction materials $y$ is determined not only by cyclone damage $X$ (targeting), but also by social status $Z$ (elite domination). I employ the following reduced-form models at the village $(v)$, clan $(g)$, and household $(i)$ levels:

$$
\begin{aligned}
& y_{v}=\alpha_{1}+\beta_{1} X_{v}+\gamma_{1} Z_{v}+\delta_{1} W_{v}+e_{v}, \\
& y_{g}=\alpha_{2}+\beta_{2} X_{g}+\gamma_{2} Z_{g}+\delta_{2} W_{g}+V+e_{g}, \\
& y_{i}=\alpha_{3}+\beta_{3} X_{i}+\gamma_{3} Z_{i}+\delta_{3} W_{i}+V+e_{i},
\end{aligned}
$$

where $W_{v}, W_{g}$, and $W_{i}$, respectively, are other village, clan, and household characteristics that affect the allocation; $V$ is village dummies; and $e_{v}, e_{g}$, and $e_{i}$ are error terms. Whether victims reconstruct or repair their dwellings without receiving construction materials certainly affects the allocations of reconstruction funds, but this endogenous decision does not appear as an explanatory variable in the reduced-form equations (1)-(3) (examining self-reconstruction is not a focus of the paper).

As village dummies fully control for village-level factors, including total construction materials allocated to the village, equations (2) and (3), respectively, focus on allocations across clans and households within the village. I also estimate equation (3), 
replacing village dummies $V$ with clan dummies $G$, which fully control for clan-level factors. If household-level factors are a driving force, then significant findings in the original equation (3), which does not control for clan-level factors - both observable and unobservable ones - must be robust to this alternative specification focusing on allocations within the clan.

I first estimate the determinants of receipt using probit for the whole sample and those of log of the amount received among recipients using Ordinary Least-Squares (OLS) in the three-year period, 2003-2005. This is a two-part, or hurdle, model commonly used in previous works on targeting (Jayne et al., 2002; Dercon and Krishnan, 2005); an alternative sample selection model is infeasible with these data, which lack the identifying instruments required to credibly estimate the selection equation. In equation (1), the dummy dependent variable takes one if there is at least one recipient household in a village, and the village means of the amount received are used to estimate the amount equation among recipient villages; equation (2) is estimated analogously. Non-temporal targeting and elite domination are measured by positive $\beta_{j}$ and $\gamma_{j}$, respectively.

With temporal targeting and elite domination, respectively, impacts of cyclone damage and social status decrease over time. To test these patterns, I employ the same two-part model in the first year, 2003, and in the first two years, 2003-2004, separately and see whether $\beta_{j}$ and $\gamma_{j}$ decrease as the time range increases from 1 year to 2 years, and to 3 years; alternatively, estimating the model in each year can be considered, but this requires using the receipt or the amount received in previous year(s) as a lagged dependent variable, the endogeneity of which cannot be controlled for with these data. For robustness check, I also estimate the determinants of the year of receipt among 
recipients in the three-year period using an ordered probit (the year of receipt of a firstrecipient household in the village- and clan-level analyses). Distinct from the over-time comparison of effects of cyclone damage and social status on receipt in the probit, the ordered-probit directly estimates their effects on the order of receipt: Temporal targeting and elite domination are measured by negative $\beta_{j}$ and $\gamma_{j}$, respectively, as the greater the dependent variable (order), the later the receipt.

I repeat all these analyses among eligible potential recipients - households with a damaged dwelling and clans containing at least one victimized household (all villages are eligible) - finding almost the same results as what are presented below. I conduct all analyses with and without considering the stratification and weighting design discussed above, finding very similar results, while significance levels improve in the former and the latter conservative results are presented below.

Although retrospective errors in the receipt of construction materials should be minimal and those in the year of receipt should be also small (those in the month of receipt could be significant), those in the amount received could be considerable. A question is whether errors are correlated with covariates. In particular, households with more damage may have felt that the amount received was too small relative to the damage and may have reported smaller amounts than the actual ones, causing a downward bias in estimated impacts of the damage. This means that estimated positive $\beta_{j}$ in the amount equation (suggesting good targeting) should be qualitatively robust.

Household-level cyclone damage $X_{i}$ is captured by the log value of total dwelling damage or two dummies for a completely destroyed and partially damaged main house, respectively. The damage value measure is comprehensive, because it covers total 
damage of all dwelling units, but its measurement errors could be considerable and systematic. Although the main house damage measure does not capture free-standing units owned by some households, retrospective errors in the damage status of each main house reported by individual households are minimal, because relief officers used the same three categories for their damage assessments (the damage status of each house was common knowledge among villagers). As shown below, results of these two damage measures are qualitatively the same, which gives me confidence about the findings' robustness. $X_{v}$ is measured by the village mean of total damage value or two variables for the proportions of households with completely destroyed and partially damaged main houses in the village, respectively; $X_{g}$ is measured analogously. When the main house damage measures are used, $\beta_{j}$ should indicate a greater marginal effect for complete damage than partial damage.

Social status $Z_{v}, Z_{g}$, and $Z_{i}$, respectively, are measured by a dummy for chief's villages, two dummies for chief's clans and non-clan leaders' clans, and two dummies for clan leaders and non-clan leaders, as defined above.

Village characteristics $W_{v}$ include village size and access, measured by the total number of households in the village (in the population) and travel time to a market (log), respectively; clan size, measured by the total number of households in the clan (in the population), is considered for clan characteristics $W_{g}$. Although it is expected that larger clans with more victims are more likely to be recipients in the village, how village size matters is ambiguous: Larger villages may be prioritized or they instead may be given a lower priority with a limited supply of funds. Geographical location certainly determines the delivery of emergency relief, but whether this is also the case for reconstruction funds 
during post-emergency periods is an empirical question. In equations (2) and (3), all geographical factors are controlled for by village dummies. Household characteristics $W_{i}$ are captured by asset holdings and demographic factors in a standard manner. ${ }^{1}$ If the allocation is determined by targeting and elite domination, as conjectured here, these household characteristics should not matter.

\section{Estimation results}

Estimation results of the models with dwelling damage value at the village, clan (mataqali), and household levels are shown in panels A, B, and C of Table 2, respectively; results with main house damage at the household level are in panel D (those at the village and clan levels are qualitatively the same as those presented in panels A and B). In each panel, results of only cyclone damage and social status are reported: ${ }^{2}$ The two-part models in 2003-2005, 2003, and 2003-2004 are in columns (1)-(2), (3), and (4)(5), respectively, where estimated marginal effects at means are reported for the probit (the analysis of the amount received in 2003 is infeasible because of the small number of observations); estimated coefficients for the ordered probit are in column (6). ${ }^{3}$

Non-temporal targeting is very significant in 2003-2005: Receipt and amount received are strongly targeted toward more severely affected victims, according to both dwelling damage value and main house damage, at the village, clan, and household levels (columns 1 and 2). In particular, the probability of being a recipient is higher by .72 and the amount received is $261 \%$ larger among households with a completely destroyed main house than others; comparable strong results are obtained at the village and clan levels (in all cases, partial main house damage exhibits much smaller impacts than complete 
destruction, as expected). Although marginal effects of dwelling damage value on receipt are small, those on the amount received are large.

There is no strong evidence of temporal targeting, however. Overall fitness of the models of receipt in 2003 and of year of receipt is weak at the village and clan levels. Only in receipt at the village level, consistent with temporal targeting, do the marginal effects of damage decrease over time, and correspondingly, the estimated coefficients of damage in the year-of-receipt equation are negative, but not statistically significant. According to both the receipt and year-of-receipt equations, clans with more severely affected victims appear to be rather late recipients; the estimated marginal effects are very small, however, and the result is not statistically significant with main house damage. A similar pattern is found at the household level, but in equation (3) with clan dummies, the estimated coefficient for dwelling damage value in the year-of-receipt equation loses statistical significance, indicating that household-level damage is not a driving force.

Strong temporal, but not non-temporal, elite domination of receipt exists at the household level: (1) the probability of receipt in 2003-2004 (but not in 2003-2005) is higher by .10-.12 among clan leaders than others (column 4); and (2) conditional on receipt in 2003-2005, the probability of receipt in 2003 and 2005 is higher and lower by about .14-.15 and .12-.13, respectively, among clan leaders than non-leaders (these are marginal effects at means based on the estimated coefficients reported in column 6). When clan dummies are used, both results hold, confirming that household-level elite status is a driving force. Although elite domination by chief's villages is nonexistent, temporal elite domination also exists at the clan level: The chief's clans are more likely to be recipients than others in 2003-2004 (about .40 marginal effects) (column 4), though 
the statistical significance is not strong (near 10\%) and the corresponding year-of-receipt equation shows weak results, as discussed above; the result in 2003-2005 is weaker (column 1).

Neither temporal nor non-temporal elite domination of amounts received exists at any level. Though the clan leader dummy exhibits a positive impact on the amount received in 2003-2004 (column 5), this is statistically significant only in models with main house damage and the result loses statistical significance with clan dummies. Nor is there evidence of domination by non-traditional elites in any form of allocation. Hence, although the regressions results on non-temporal targeting are consistent with earlier descriptive findings, this is not the case for temporal targeting and non-temporal/temporal elite domination. Controlling for targeting as a primary allocation mechanism is crucial to identify elite domination as a secondary allocation mechanism.

\section{Discussions}

How does elite domination of reconstruction funds differ from that of emergency relief? Since crop damage is not very observable to other households and everyone demands food aid, there exist significant room and demand for capture; Takasaki (forthcoming), however, finds that neither clan leaders nor chief's clans dominate food aid, because in a closely knit kin society, capturing relief allocated as part of risk sharing greatly deteriorates elites' reputation (Dercon and Krishnan, 2005 also show that food aid is shared within villages in Ethiopia).

In contrast to emergency food aid, the following relationships hold for housing construction materials. First, because only households with a damaged dwelling demand construction materials, capturing by non-victims is limited; indeed, leakage is minimal 
(Takasaki, forthcoming finds a similar pattern in the receipt of tarpaulins). Second, information problems in housing damage among villagers and relief officers are very small. This precludes local elites from receiving larger benefits in any period, because the amount provisioned can be well determined based on the damage. Third, at the same time, the lumpiness of construction materials (especially for new house building) makes the allocation to recipients much more 'discrete.' Fourth, accordingly, a limited supply of construction materials gives rise to significant under-coverage, especially during early periods, making considerable room for local elites' early receipt of benefits.

How capture and norms work depends on the benefit-cost calculation of local elites and non-elites, respectively. For both elites and non-elites, benefits of receiving construction materials are much higher than those of receiving food aid (the mean value of construction materials received per adult equivalent among recipients is 6.5 times the mean value of food aid received per capita, as reported by Takasaki, forthcoming). Benefits peak in 2004 when the amount provisioned - especially for new house building - started to augment. For elites, the social cost of capturing construction materials must be much higher than that of capturing food aid, but that of manipulating the timing of receipt by one year or so should be much smaller than that of manipulating the recipients themselves. Similarly, for non-elites, the cost of waiting for receipt for another year or so might be smaller than their social cost of not conforming to cultural norms. As such, both capture and norms are consistent with the observed pattern of temporal elite domination. As traditional elites exercise their power the most and are prioritized highest in the village, clan leaders and elite clans are dominants.

\section{Conclusion}


This paper shed new light on the local allocation of natural disaster reconstruction funds by highlighting potential elite capture among cyclone victims in rural Fiji. Its major findings suggest the following implications for disaster management in developing areas. First, with good information about damage in the reconstruction phase, targeting performance is strong and local elites' capturing of larger benefits is not an issue. Effective targeting through good management of data and information (Amin and Goldstein, 2008) is crucial to prevent elite capture. Second, still, a scarce supply of reconstruction funds leads to local elites' early receipt of benefits. Timely provision is thus of great importance not only to better support disaster victims, but also to reduce potential early capture. Third, in kin-based societies like Fiji, traditional elite status is a source of power for capturing and shapes cultural norms for consensual prioritizing. Development agents should pay attention to elite individuals and groups in their efforts to achieve equity within villages. Fourth, identifying local elites and their domination is more difficult than evaluating targeting performance. Carefully designing post-disaster surveys to collect direct measures of elite status for econometric analysis would be very useful for a more thorough exploration of capture problems. Last, differentiating between capture and norms is a big empirical challenge. More research on the process of local benefit allocation is needed. Understanding allocation mechanisms beyond targeting can greatly help disaster management and post-disaster development.

\section{Notes}

${ }^{1}$ Household characteristics include land holdings (log), fishing capital (log), a dummy for secondary education among adults, household adult equivalent size (log), proportions of children and elderly, age of household head $(\log )$, and a dummy for female head. All of 
these are measured at the time of interviews. It is better to use measures before or right after the cyclone, but such data are lacking. In particular, land holding and fishing capital can be endogenous, because the receipt of construction materials can alter household investment decisions. To address this problem, I estimate models excluding these two assets, finding very similar results on all remaining variables. For the same reason, income is not included, though these household characteristics control for permanent income. Note also that village dummies control for income inequality (also in equation 2). ${ }^{2}$ Findings about village, clan, and household characteristics are as follows. Although the allocation is neutral to village access, smaller villages are more likely to be recipients in 2003-2004, but not in 2003-2005. As expected, larger clans are more likely to be recipients in 2003-2004 and 2003-2005; the results are statistically significant, however, only in the models with main house damage. Almost no household characteristics are strong determinants in any form of allocations; the only exception is that households with more children (in proportion) tend to receive larger amounts in 2003-2004 and 2003-2005. Because household size, as well as other demographic factors, is controlled for separately, this result gives evidence that allocations favor children. When household characteristics are not controlled for, the results of cyclone damage and social status are very similar to the findings presented here, indicating that the correlations of social status and household characteristics are not a main concern in these analyses.

${ }^{3}$ Equation (2) can be applied only to villages in which there exist across-clan variations in receipt during the period of interest in the probit and the years of receipt among recipient clans in the ordered probit; without such variations, village dummies perfectly 
predict them. Analogously, equation (3) can be applied only to villages with sufficient across-household variations. Accordingly, there are far fewer observations for these analyses. The numbers of observations for the analyses conditional on receipt - OLS and ordered probit - further decline, especially in 2003. I also estimated equation (2) at the tokatoka level, finding very similar results.

\section{References}

Amin, S. and Goldstein, M. (2008) Data Against Natural Disasters: Establishing Effective Systems for Relief, Recovery, and Reconstruction. (Washington, D.C.: World Bank).

Araujo, M. C., Ferreira, F. H. G., Lanjouw, P. and Ozler, B. (2008) Local Inequality and Project Choice: Theory and Evidence from Ecuador. Journal of Public Economics, 92(5-6), pp.1022-46.

Bardhan, P. and Mookherjee, D. (2000) Capture and Governance at Local and National Levels. American Economic Review, 90(2), pp.135-39.

Bardhan, P. and Mookherjee, D. (2006) Pro-poor Targeting and Accountability of Local Governments in West Bengal. Journal of Development Economics, 79(2), pp.30327.

Bertram, G. (1986) Sustainable development in Pacific microeconomies. World Development, 14(7), pp.809-822.

Campbell, J. R. (1984) Dealing With Disaster: Hurricane Response in Fiji. (Honolulu: Pacific Islands Development Program, East-West Centre). 
Dasgupta, A. and Beard, V. A. (2007) Community Driven Development, Collective Action and Elite Capture in Indonesia. Development and Change, 38(2), pp.22949.

de Ville de Goyet, C. (2008) Information gaps in relief, recovery, and reconstruction in the aftermath of natural disasters, in: S. Amin, M. Goldstein (eds.) Data Against Natural Disasters: Establishing Effective Systems for Relief, Recovery, and Reconstruction, (Washington, D.C.: World Bank), pp. 23-58.

Dercon, S. and Krishnan, P. (2005) Food Aid and Informal Insurance, in: S. Dercon (ed.) Insurance Against Poverty, (Oxford and New York: Oxford University Press), pp. 305-329.

Galasso, E. and Ravallion, M. (2005) Decentralized Targeting of an Antipoverty Program. Journal of Public Economics, 89(4), pp.705-27.

Jayne, T. S., Strauss, J., Yamano, T. and Molla, D. (2002) Targeting of Food Aid in Rural Ethiopia: Chronic Need or Inertia? Journal of Development Economics, 68(2), pp. $247-88$.

Khwaja, A. I. (2001) Can Good Projects Succeed in Bad Communities? Collective Action in the Himalayas. Faculty Research Working Papers Series RWP01-043, Harvard University, John F. Kennedy School of Government.

Lanjouw, P. and Ravallion, M. (1999) Benefit Incidence and the Timing of Program Capture. Policy Research Working Paper Series 1956, World Bank.

Leeson, P. T. and Sobel, R. S. (2008) Weathering Corruption. Journal of Law and Economics, 51(4), pp.667-81. 
Mansuri, G. and Rao, V. (2004) Community-Based and -Driven Development: A Critical Review. World Bank Research Observer, 19(1), pp.1-39.

McKenzie, E., Prasad, B. and Kaloumaira, A. (2005) Economic impact of natural disasters on development in the Pacific: Volume 1 Research report. The University of the South Pacific.

Morris, S. S. and Wodon, Q. (2003) The Allocation of Natural Disaster Relief Funds: Hurricane Mitch in Honduras. World Development, 31(7), pp.1279-89.

National Disaster Management Office (2003) Report on Tropical Cyclone Ami. Ministry of Regional Development, Fiji.

Platteau, J.-P. and Abraham, A. (2002) Participatory Development in the Presence of Endogenous Community Imperfections. Journal of Development Studies, 39(2), pp.104-36.

Rao, V. and Ibáňez, A. M. (2003) The social impact of social funds in Jamaica: a mixedmethods analysis of participation, targeting and collective action in community driven development. Policy Research Working Paper Series 2970, World Bank.

Ravuvu, A. (1983) Vaka I Taukei: The Fijian Way of Life. (Suva: Institute of Pacific Studies).

Takasaki, Y. (forthcoming) Targeting cyclone relief within the village: kinship, sharing, and capture. Economic Development and Cultural Change.

Turner, J. W. (1992) Ritual, habitus, and hierarchy in Fiji. Ethnology, 31(4), pp.291-302.

World Bank (2002) Reaching the poor: a renewed strategy for rural development. (Washington, D.C.: World Bank). 
Table 1. Means of elite status, housing damage, construction materials, and reconstruction by receipt.

\begin{tabular}{|c|c|c|c|c|}
\hline & All & Non-recipients & Recipients & $\begin{array}{c}\text { Mean. } \\
\text { test } \\
\text { (p-value) }\end{array}$ \\
\hline \multicolumn{5}{|l|}{ A. Village } \\
\hline Chief's village dummy & $0.35(0.48)$ & $0.40(0.55)$ & $0.34(0.48)$ & 0.804 \\
\hline Non-clan leaders dummy & $1.00(0.00)$ & $1.00(0.00)$ & $1.00(0.00)$ & n.a. \\
\hline Damaged dwelling dummy & $1.00(0.00)$ & $1.00(0.00)$ & $1.00(0.00)$ & n.a. \\
\hline Proportion of damaged dwelling & $0.64(0.21)$ & $0.37(0.24)$ & $0.68(0.18)$ & 0.001 \\
\hline Proportion of completely destroyed main houses & $0.21(0.16)$ & $0.07(0.08)$ & $0.23(0.16)$ & 0.031 \\
\hline Proportion of partially damaged main houses & $0.34(0.15)$ & $0.26(0.15)$ & $0.35(0.14)$ & 0.162 \\
\hline Proportion of damaged free-standing units & $0.55(0.21)$ & $0.33(0.22)$ & $0.58(0.19)$ & 0.009 \\
\hline Village mean of total dwelling damage (F\$) & $1160(771)$ & $287(203)$ & $1275(744)$ & 0.006 \\
\hline Construction materials receipt dummy & $0.88(0.32)$ & $0.00(0.00)$ & $1.00(0.00)$ & n.a. \\
\hline Village mean of construction materials received (F\$) & 775 (849) & $0(0)$ & 877 (852) & 0.006 \\
\hline Proportion of new main house building & $0.10(0.1)$ & $0.02(0.0)$ & $0.12(0.1)$ & 0.028 \\
\hline No. observations & 43 & 5 & 38 & \\
\hline \multicolumn{5}{|l|}{ B. Clan } \\
\hline Chief's clan dummy & $0.17(0.38)$ & $0.10(0.31)$ & $0.23(0.42)$ & 0.049 \\
\hline Non-clan leaders dummy & $0.55(0.50)$ & $0.40(0.49)$ & $0.67(0.47)$ & 0.001 \\
\hline Damaged dwelling dummy & $0.88(0.32)$ & $0.75(0.44)$ & $1.00(0.00)$ & 0.000 \\
\hline Proportion of damaged dwelling & $0.59(0.32)$ & $0.41(0.34)$ & $0.73(0.21)$ & 0.000 \\
\hline Proportion of completely destroyed main houses & $0.18(0.23)$ & $0.06(0.12)$ & $0.27(0.26)$ & 0.000 \\
\hline Proportion of partially damaged main houses & $0.32(0.28)$ & $0.28(0.30)$ & $0.34(0.26)$ & 0.189 \\
\hline Proportion of damaged free-standing units & $0.49(0.31)$ & $0.34(0.32)$ & $0.62(0.25)$ & 0.000 \\
\hline Clan mean of total dwelling damage ( $F \$)$ & $994(1165)$ & $352(539)$ & $1538(1274)$ & 0.000 \\
\hline Construction materials receipt dummy & $0.54(0.50)$ & $0.00(0.00)$ & $1.00(0.00)$ & n.a. \\
\hline Clan mean of construction materials received $(\mathrm{F} \$)$ & $680(1366)$ & $0(0)$ & $1257(1654)$ & 0.000 \\
\hline Proportion of new main house building & $0.08(0.2)$ & $0.01(0.1)$ & $0.15(0.2)$ & 0.000 \\
\hline No. observations & 146 & 67 & 79 & \\
\hline \multicolumn{5}{|l|}{ C. Household } \\
\hline Clan leader dummy & $0.19(0.40)$ & $0.20(0.40)$ & $0.18(0.38)$ & 0.412 \\
\hline Non-clan leader dummy & $0.10(0.30)$ & $0.09(0.29)$ & $0.14(0.34)$ & 0.055 \\
\hline Damaged dwelling dummy & $0.62(0.49)$ & $0.50(0.50)$ & $0.98(0.15)$ & 0.000 \\
\hline Completely destroyed main house dummy & $0.19(0.39)$ & $0.09(0.28)$ & $0.48(0.50)$ & 0.000 \\
\hline Partially damaged main house dummy & $0.34(0.47)$ & $0.32(0.46)$ & $0.42(0.50)$ & 0.003 \\
\hline Damaged free-standing units dummy & $0.53(0.50)$ & $0.41(0.49)$ & $0.86(0.35)$ & 0.000 \\
\hline Total dwelling damage (F\$) & $1074(2138)$ & $466(1160)$ & $2881(3134)$ & 0.000 \\
\hline Construction materials receipt dummy & $0.25(0.43)$ & $0.00(0.00)$ & $1.00(0.00)$ & n.a. \\
\hline Construction materials received ( $\mathrm{F} \$$ ) & 685 (1983) & $0(0)$ & 2821 (3191) & 0.000 \\
\hline New main house building dummy & $0.09(0.3)$ & $0.03(0.2)$ & $0.28(0.5)$ & 0.000 \\
\hline No. observations & 903 & 676 & 227 & \\
\hline
\end{tabular}

Note - Standard deviations are shown in parentheses. Mean test results with a $5 \%$ significance level are bolded. 
Table 2. Allocation of construction materials.

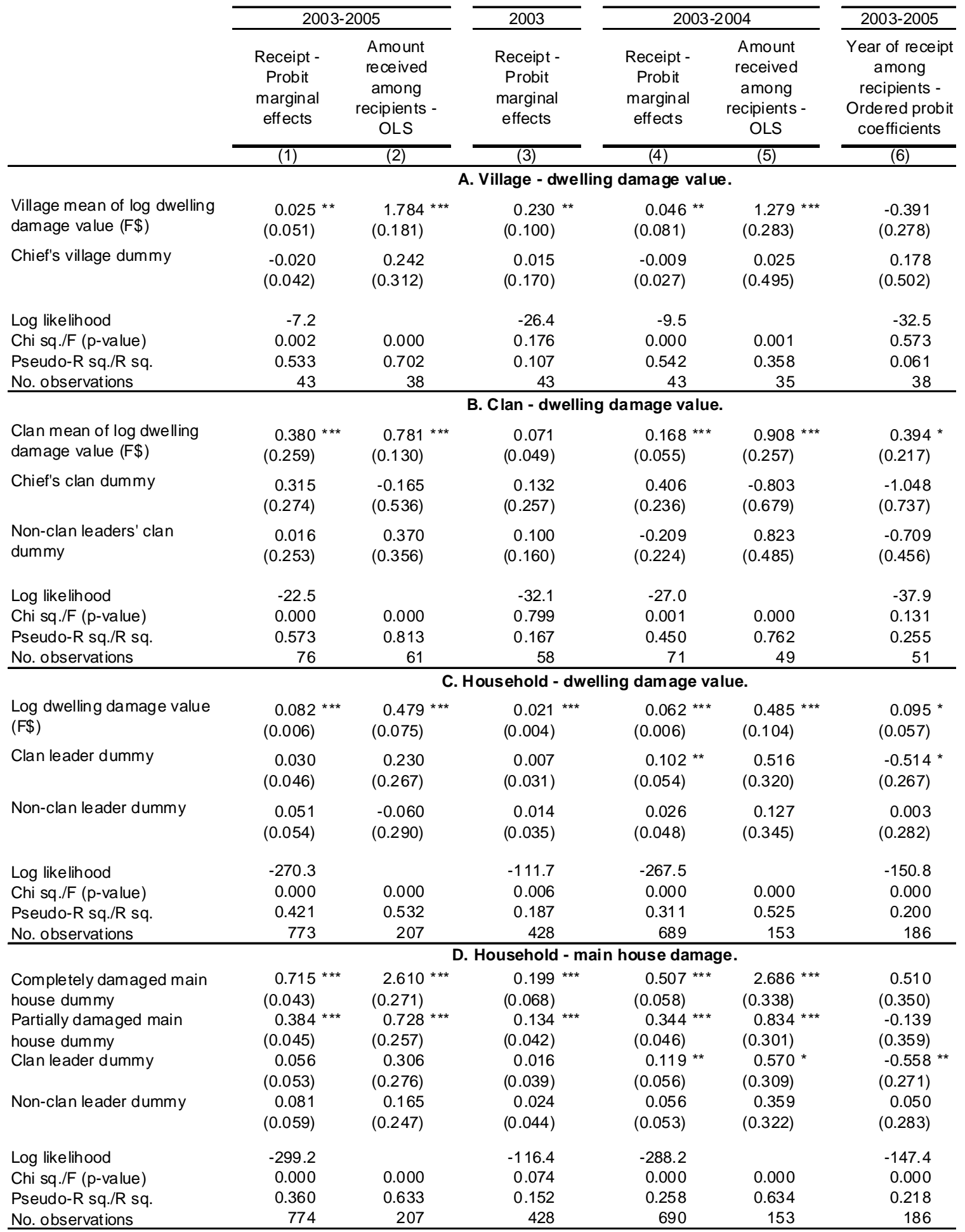

* $10 \%$ significance, ${ }^{\star \star} 5 \%$ significance, ${ }^{\star} \star \star 1 \%$ significance. Columns (1), (3), and (4) are marginal effects at means in probit estimates with standard errors in parentheses; columns (2) and (5) are OLS estimates conditional on receipt with robust standard errors in parentheses; and column (6) is ordered probit estimates conditional on receipt with standard errors in parentheses. Other controls which are not shown here are village characteristics in panel A, clan characteristics in panel B, household characteristics in panels $C$ and D, village dummies in panels B and C, and constant in columns (2), (5), and (6). 
Figure 1. Fijian kin strcuture.

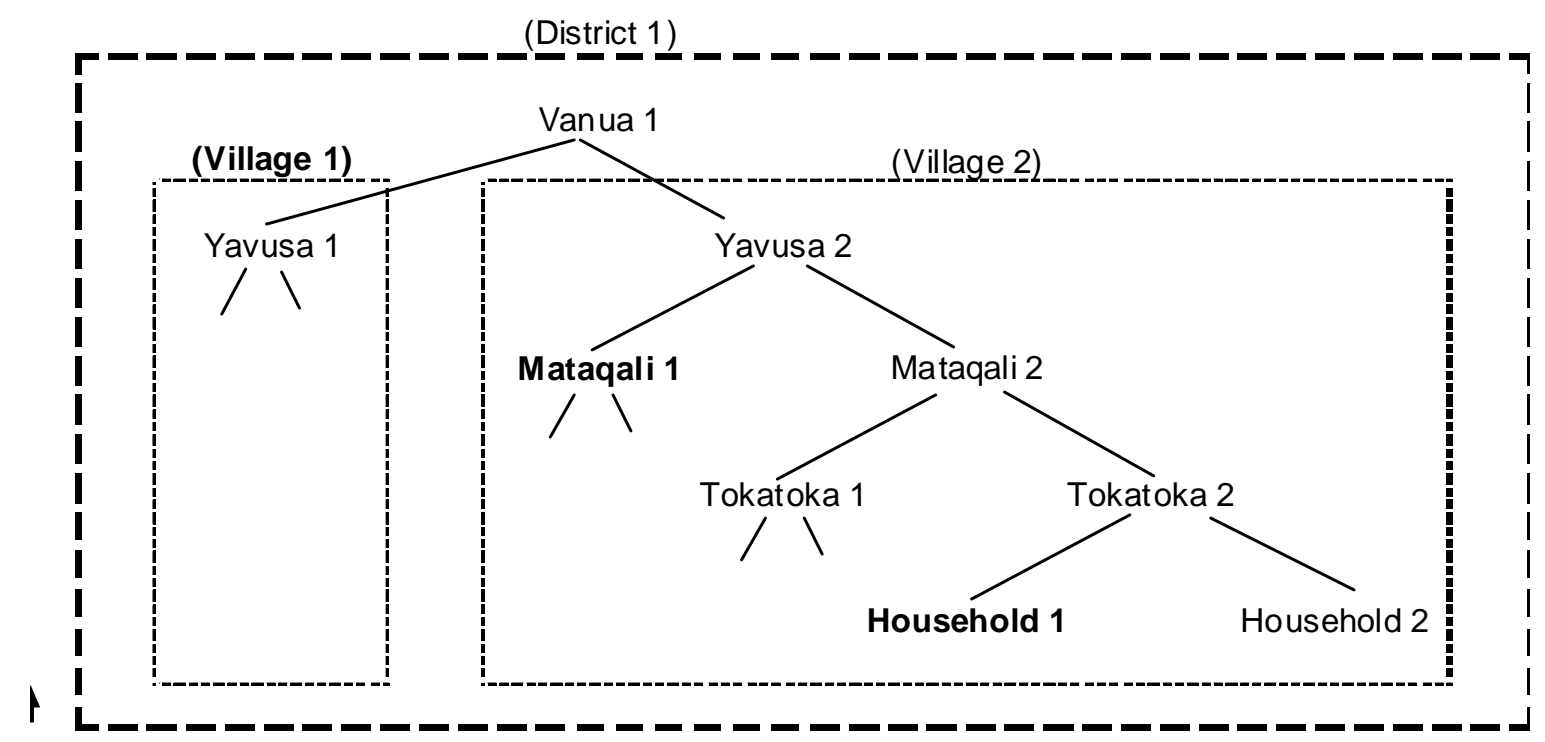

Note: Chief's village, chief's clan, and clan leader are bolded. 
Figure 2. Evolution of provisions of construction materials

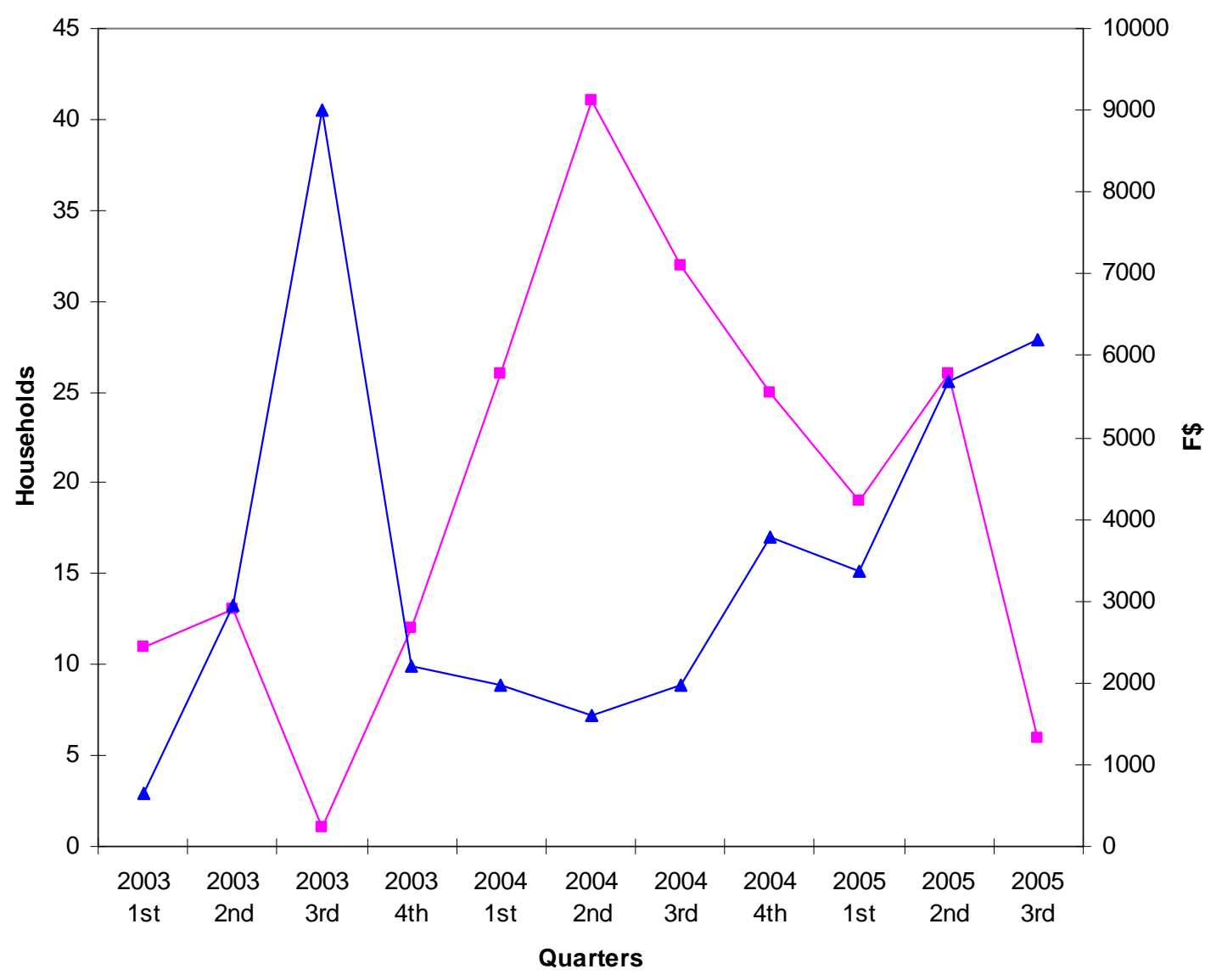

$\longrightarrow$ No. of recipients $\longrightarrow$ Mean amount of construction materials among recipients 